\title{
PENGARUH KEPEMIMPINAN DAN LINGKUNGAN KERJA TERHADAP KINERJA KARYAWAN PT VICTORY CHINGLUH INDONESIA DIVISI QUALITY
}

\author{
${ }^{1 *}$ Tarwijo, ${ }^{2}$ Dini Fatmawati, ${ }^{3}$ Isep Amas Priatna \\ Universitas Pamulang, Tangerang, Banten, Indonesia \\ *dosen01476@unpam.ac.id, dosen01629@unpam.ac.id
}

\begin{abstract}
Abstrak
Tujuan penelitian ini adalah untuk mengetahui pengaruh kepemimpinan dan lingkungan kerja terhadap kinerja karyawan PT. Victory Chingluh Indonesia Divisi Quality. Metode yang digunakan adalah metode asosiatif. Analisis data menggunakan uji validitas, uji reliabilitas, uji asumsi klasik, analisis regresi, analisis koefisien korelasi, analisis koefisien determinasi dan uji hipotesis. Hasil penelitian ini adalah bahwa kepemimpinan dan lingkungan kerja berpengaruh signifikan terhadap kinerja karyawan PT. Victory Chingluh Indonesia Divisi Quality dengan persamaan regresi $Y=7,374+0,230 X_{1}+0,628 X_{2}$. Hasil penelitian secara simultan diketahi dengan uji hipotesis diperoleh nilai $F_{\text {hitung }}>F_{\text {tabel }}$ atau $(65,719>2,760)$. Dengan demikian $\mathrm{H}_{0}$ ditolak dan $\mathrm{H}_{3}$ diterima.
\end{abstract}

Kata Kunci: Kepemimpinan, Lingkungan Kerja, Kinerja Karyawan

The purpose of this study is to find out the influence of leadership and the work environment on the performance of employees of PT. Victory Chingluh Indonesia Quality Division. The method used is the associative method. Data analysis uses validity tests, reliability tests, classical assumption tests, regression analysis, correlation coefficient analysis, determination coefficient analysis and hypothesis tests. The result of this study is that leadership and work environment have a significant effect on the performance of EMPLOYEES of PT. Victory Chingluh Indonesia Division quality with regression equation $Y=7.374+0.230 \mathrm{X} 1+0.628 \mathrm{X} 2$. The results of the study simultaneously served with the hypothesis test obtained the value F calculated $>$ F table or $(65,719>2,760)$. Thus HO is rejected and $\mathrm{H} 3$ is accepted.

Keywords: Leadership, Work Environment, Employee Performance 


\section{PENDAHULUAN}

Pegawai suatu organisasi merupakan asset terpenting dalam pencapaian tujuan suatu organisasi, dimana bila pegawai mampu menghasilkan kinerja yang baik, maka dapat memberikan kontribusi besar dalam menjalankan aktivitas suatu organisasi. Dengan kinerja yang baik maka setiap pegawai dapat menyelesaikan segala beban perusahaan dengan efektif dan efisien sehingga masalah yang terjadi pada perusahaan/instansi dapat teratasi dengan baik. Kinerja pegawai juga dapat dilihat dari aspek kualitas kerja, kuantitas kerja, pelaksanaan tugas, tanggung jawab dan inisiatif.

Melalui perencanaan Sumber Daya Manusia yang matang, kinerja yang sudah ada dapat ditingkatkan. Hal ini dapat diwujudkan melalui adanya penyesuaian, seperti peningkatan kepemimpinan dan lingkungan kerja yang baik. Sehingga setiap karyawan dapat menghasilkan sesuatu yang berkaitan langsung dengan kepentingan organisasi.

Chingluh group memulai operasi bisnisnya di tahun 1969 dengan mendirikan Taiwan Ching Luh Shoes Co. Ltd oleh pendirinya yaitu Mr. Su Chingluh sudah lebih dari 40 tahun membangun reputasi bisnisnya dan kemampuan tehnisnya mulai dari Taiwan dan mengembangkan bisnisnya dengan kelas dunia di China, Vietnam dan terakhir di Indonesia. Di Indonesia sendiri PT. Victory Chingluh Indonesia beralamat di Jl. Otonom Pasar Kemis No. $48 / 49$ Rt. 003/004 Pasar Kemis, Tangerang, Banten 15560. Merupakan perusahaan yang bergerak di bidang footwear manufactures yang didirikan pada tahun 2009 dengan peletakan batu pertama yang di laksanakan pada tanggal 19 Maret 2009. Setelah 12 bulan persiapan, satu fasilitas mahakarya yang terbaru dari Ching Luh Group beroperasi di bulan September 2010.

Kegiatan PT. Victory Chingluh Indonesia dirancang berdasarkan konsep ramah lingkungan, pabrik yang efisien, dan tenaga kerja yang terlatih untuk memproduksi sepatu dengan merek Nike yang berkualitas tinggi untuk para pelanggan. Dalam mencapai kegiatannya terebut, terdapat kerjasama yang luar biasa antar divisi yang ada di PT. Victory Chingluh Indonesia.

Kepemimpinan seorang pemimpin dalam suatu organisasi sangat penting karena pemimpin memiliki peranan yang strategis dalam mencapai tujuan perusahaan. Menurut Sutikno (2014:16) berpendapat bahwa "Kepemimpinan adalah sebuah proses dimana seorang pemimpin dapat secara langsung membimbing dan mempengaruhi perilaku dan pekerjaan lainnya untuk menuju pencapaian dalam situasi tertentu".

Hasil pengamatan langsung ditemukan permasalahan terkait data kepemimpinan yaitu aspek keteladanan karyawan yang menjawab setuju 25 orang atau $83.3 \%$ dan yang tidak setuju 5 orang atau $16,7 \%$. Data aspek kewibawaan karyawan yang menjawab setuju 20 orang atau $66,6 \%$ dan yang tidak setuju 10 orang atau $33,4 \%$. Selanjutnya aspek pendelegasian tugas yang menjawab setuju 26 orang atau $86,6 \%$ dan yang tidak setuju 4 orang atau $13,4 \%$.

Tidak hanya itu, permasalahan kepemimpinan dalam hal mengambil keputusan tidak sesuai dengan buku PKB (Perjanjian Kerja Bersama) PT. Victory Chingluh Indonesia akan berdampak buruk bagi karyawan, seperti ditemukan kasus demosi, rotasi dan mutasi yang tidak sesuai dengan PKB yaitu pemimpin tidak dapat mengambil keputusan sepihak tanpa adanya mediasi dari manajemen dan pihak terkait yang akan di demosi, rotasi dan mutasi maka pengambilan keputusan tersebut tidak sah, hal tersebut terlihat pada aspek pengambilan keputusan yang menjawab setuju 19 orang atau $63,6 \%$ dan yang tidak setuju 11 orang atau 36,7\%. Permasalahan kepemimpinan juga ditemukan dalam aspek motivasi karyawan yang menjawab setuju 25 orang atau 83,3\% dan yang tidak setuju 5 orang atau 16,7\%.

Lingkungan kerja menunjuk pada hal-hal yang berada di sekeliling dan melingkupi karyawan disuatu perusahaan. 
Menurut Sunyoto (2015:43) bependapat bahwa "Lingkungan kerja adalah segala sesuatu yang ada disekitar para pekerja dan yang dapat mempengaruhi dirinya dalam menjalankan tugas-tugas yang dibebankan misalnya kebersihan, penerangan, suara bising dan lain-lain". Hasil pengamatan langsung ditemukan permasalahan terkait variabel lingkungan kerja yaitu aspek penerangan, jumlah lampu yang standarnya 45 unit ternyata aktualnya 36 unit artinya minimnya penerangan yang ada dilingkungan kerja mengakibatkan karyawan sulit mendeteksi kerusakan sepatu yang sedang dibuat sehingga sering ditemukan sepatu yang kelolosan reject. Selanjutnya pengaturan suhu yang yang kurang sejuk, jumlah blower yang seharusnya 20 unit ternyata aktualnya hanya 10 unit, oksigen yang dibutuhkan pekerja kurang baik karena udara atau hawa panas akan mengakibatkan menurunnya kualitas sepatu yang sedang di produksi. Kelembaban diruangn juga kurang terjaga karena AC yang seharusnya 15 unit hanya tersedia 10 unit. Jumlah mesin produksi yang seharusnya 25 unit ternyata aktualnya adalah 30 unit, hal ini mengakibatkan kebisingan yang cukup keras sehingga mengganggu konsentrasi dalam bekerja, kebisingan dapat menimbulkan bunyi yang menggungu telinga terutama dalam jangka panjang bunyi tersebut dapat menggangu ketenangan bekerja. Permasalah sirkulasi udara juga ditemukan yang seharusnya jumlah ventilasi 25 unit hanya ada 17 unit membuat ruangan pengap.

Kinerja merupakan gambaran mengenai tingkat pencapaian pelaksanaan suatu program kegiatan atau kebijakan dalam mewujudkan sasaran, tujuan, visi dan misi organisasi yang dituangkan melalui perencanaan strategis suatu organisasi. Menurut Abdullah (2014:3-4) berpendapat bahwa "Kinerja adalah prestasi kerja yang merupakan hasil implementasi rencana kerja yang dibuat oleh institusi yang dilaksanakan oleh pemimpin dan karyawan (SDM) yang bekerja di institusi itu baik pemerintah maupun perusahaan (bisnis) untuk mencapai tujuan organisasi". Melalui penelitain awal, peneliti mendapatkan data produksi sepatu PT. Victory Chingluh Indonesia Divisi Quality yang menunjukkan hasil produksi Tahun 20172019 dengan jumlah yang fluktuasi. Tahun 2017 mencapai produksi sebanyak 427.110. Tahun 2018 mencapai produksi sebanyak 449.890 dan pada tahun 2019 mencapai produksi sebanyak 352.398. Hasil pengamatan langsung tersebut ditemukan permasalahan terkait variabel kinerja yaitu kinerja karyawan yang belum maksimal karena kualitas sepatu yang dihasilkan rendah pada setiap bulannya. Permasalaha kuantitas sepatu yang di produksi mengalami punurunan dan masih belum tercapai sesuai dengan target yang telah ditentukan perusahaan.

Berdasarkan latar belakang yang dikemukakan diatas, maka penulis melakukan penelitian yang berjudul "Pengaruh Kepemimpinan dan Lingkungan Kerja Terhadap Kinerja Karyawan PT. Victory Chingluh Indonesia Divisi Quality".

\section{TINJAUAN PUSTAKA}

\section{Kepemimpinan}

Menurut Amirullah (2015:167) bependapat "kepemimpinan adalah orang yang memiliki wewenang untuk memberi tugas, mempunyai kemampuan untuk membujuk dan mempengaruhi orang lain dengan melalui pola hubungan yang baik guna mencapai tujuan yang telah ditentukan". Berdasaarkan definisi kepemimpinan diatas bahwa kepemimpinan adalah kemampuan seseorang dalam mempengaruhi, mendorong dan mengendalikanorang lainataubawahan untuk bisa melakukansesuatu pekerjaanatas kesadarannya dan sukarela dalam mencapai suatu tujuan tertentu.

\section{Lingkungan Kerja}

$$
\text { Menurut Sunyoto }
$$
bependapat "lingkungan Kerja adalah segala sesuatu yang ada disekitar para 
pekerja dan yang dapat mempengaruhi dirinya dalam menjalankan tugas-tugas yang dibebankan misalnya kebersihan, peneranga, suara bising dan lain-lain". Menurut Nitisemito dalam Gardjito (2014:3) bependapat “Lingkungan Kerja adalah segala sesuatu yang ada disekitar para pekerja dan dapat mempengaruhi dirinya dalam menjalankan tugas-tugas yang dibebankan". Berdasarkan definisi tersebut dapat diketahui bahwa lingkungan kerja ialah kondisi atau situasi yang mempengaruhi cukup besar terhadap pegawai dalam melakukan pekerjaan atau terhadap jalannya operasi perusahaan.

\section{Kinerja}

Menurut Abdullah (2014:3-4) berpendapat "kinerja adalah suatu prestasi kerja yang merupakan implementasi rencana kerja yang dibuat oleh institusi yang dilaksanakan oleh pemimpin dan karyawan (SDM) yang bekerja di institusi itu baik pemerintah maupun perusahaan (bisnis) untuk mencapai tujuan organisasi". Berdasarkan dari beberapa pengertian menurut beberapa ahli diatas maka penulis menyimpulkan bahwa kinerja pegawai adalah catatan tentang hasilhasil kerja yang diperoleh dari fungsifungsi pekerjaan atau kegiatan tertentu selama kurun waktu tertentu.

\section{METODE PENELITIAN}

Populasi dalam penelitian ini adalah karyawan PT. Victory Chingluh Indonesia Divisi Quality yang berjumlah 64 karyawan atau responden dan sampel yang digunakan adalah seluruh karyawan PT. Victory Chingluh Indonesia Divisi Quality yang berjumlah 64 karyawan. Pengumpulan Data dilakukan melalui observasi, penyebaran kuesioner, dokumentasi dan studi kepustakaaan. Analisis data yang dilakukan meliputi uji instrument data, uji asumsi klasik, analisis deskriptif, analisis regresi sederhana dan berganda, analisis koefesien determinasi, analisis korelasi, dan uji hipotesis.

\section{HASIL DAN PEMBAHASAN}

1. Pengaruh Kepemimpinan $\left(X_{1}\right)$ Terhadap Kinerja Karyawan $(Y)$.

Berdasarkan hasil penelitian ini didapatkan bahwa variabel kepemimpinan $\left(X_{1}\right)$ memiliki pengaruh terhadap Kinerja $(\mathrm{Y})$ pada karyawan PT. Victory Chingluh Indonesia Divisi Quality. Pengaruh kepemimpinan terhadap kinerja karyawan dapat dijelaskan dengan beberapa faktor. Kepemimpinan pernyataan yang paling lemah yaitu perilaku pemimpin selama ini meberikan suri tauladan yang baik, dimana hanya mencapai rata-rata score sebesar 3,39. Untuk lebih baik lagi maka pimpinan hendaknya mampu berperilaku yang baik sehingga dapat dijadikan contoh oleh karyawan.

Berdasarkan hasil analisis, diperoleh nilai persamaan regresi $\mathrm{Y}=$ $20,705+0,572 \times 1$, koefisien korelasi sebesar 0,620 artinya kedua variabel mempunyai tingkat hubungan yang kuat. Nilai determinasi atau kontribusi pengaruh sebesar 0,385 atau sebesar $38,5 \%$ sedangkan sisanya sebesar $61,5 \%$ dipengaruhi oleh faktor lain. Uji hipotesis diperoleh nilai $\mathrm{t}$ hitung $>\mathrm{t}$ tabel atau $(6,226>1,999)$. Dengan demikian H0 ditolak dan H1 diterima artinya terdapat pengaruh yang signifikan secara parsial antara kepemimpinan terhadap kinerja karyawan pada PT. Victory Chingluh Indonesia Divisi Quality.

2. Pengaruh Lingkungan Kerja $\left(X_{2}\right)$ Terhadap Kinerja Karyawan (Y)

Berdasarkan hasil penelitian ini didapatkan bahwa variabel lingkungan kerja $\left(X_{2}\right)$ memiliki pengaruh terhadap Kinerja (Y) pada karyawan PT. Victory Chingluh Indonesia Divisi Quality. Pengaruh lingkungan kerja terhadap kinerja karyawan dapat dijelaskan dengan beberapa faktor. Lingkungan kerja pernyataan yang paling lemah yaitu penerangan ditempat kerja cukup baik dan tidak menyilaukan sehingga mendukung aktivitas kerja, dimana 
hanya mencapai rata-rata score sebesar 3,38. Untuk lebih baik lagi perusahaan harus memperbaiki fasilitas penerangan sesuai kebutuhan agar mampu melancarkan aktifitas pekerjaan karyawan.

Berdasarkan hasil pengujian, diperoleh nilai persamaan regresi $\mathrm{Y}=$ $11,637+0,761 X_{2}$, koefisien korelasi sebesar 0,800 artinya kedua variabel mempunyai tingkat hubungan yang sangat kuat. Nilai determinasi atau kontribusi pengaruh sebesar 0,641 atau sebesar $64,1 \%$ sedangkan sisanya sebesar $35,9 \%$ dipengaruhi oleh faktor lain. Uji hipotesis diperoleh nilai $\mathrm{t}$ hitung $>\mathrm{t}$ tabel atau $(10,513>1,999)$. Dengan demikian $\mathrm{H} 0$ ditolak dan $\mathrm{H} 2$ diterima artinya terdapat pengaruh yang signifikan secara parsial antara lingkungan kerja terhadap kinerja karyawan pada PT. Victory Chingluh Indonesia Divisi Quality.

3. Pengaruh Kepemimpinan $\left(X_{1}\right)$ dan Lingkungan Kerja $\left(X_{2}\right)$ Terhadap Kinerja Karyawan (Y)

Berdasarkan hasil penelitian ini didapatkan bahwa variabel kepimpinan (X1) dan variabel lingkungan kerja (X2) memiliki pengaruh terhadap Kinerja $(\mathrm{Y})$ pada karyawan PT. Victory Chingluh Indonesia Divisi Quality. Dalam variabel kinerja karyawan pernyataan yang paling lemah adalah nomor 1 yaitu kualitas pekerjaan yang dihasilkan akan mempengaruhi promosi jabatan, dimana hanya mencapai rata-rata score sebesar 3,39. Untuk lebih baik lagi perusahaan hendaknya memberikan reward kepada karyawan yang memiliki kemampuan menciptakan produk yang berkualitas.

Berdasarkan hasil penelitian, menunjukkan bahwa kepemimpinan (X1) dan lingkungan kerja (X2) berpengaruh positif terhadap kinerja karyawan dengan diperoleh persamaan regresi $Y=7,374+$ $0,230 \times 1+0,628 X 2$. Nlai koefisien korelasi atau tingkat pengaruh antara variabel bebas dengan variabel terikat diperoleh sebesar 0,826 artinya memiliki memiliki hubungan yang sangat kuat. Nilai koefisien determinasi atau kontribusi pengaruh secara simutan sebesar $68,3 \%$ sedangkan sisanya sebesar $31,7 \%$ dipengaruhi oleh faktor lain. Uji hipotesis diperoleh nilai $\mathrm{F}$ hitung $>$ Ftabel atau $(65,719>2,760)$. Dengan demikian H0 ditolak dan H3 diterima. Artinya terdapat pengaruh yang signifikan secara simultan antara kepemimpinan dan lingkungan kerja terhadap kinerja karyawan pada PT. Victory Chingluh Indonesia Divisi Quality.

\section{KESIMPULAN DAN SARAN Simpulan}

Berdasarkan uraian pada bab-bab sebelumnya, dan dari hasil analisis serta pembahasan mengenai Pengaruh Kepemimpinan dan Lingkungan Kerja terhadap Kinerja Karyawan PT. Victory Chingluh Indonesia Divisi Quality, sebagai berikut:

1. Kepemimpinan berpengaruh signifikan terhadap kinerja karyawan PT. Victory Chingluh Indonesia Divisi Quality dengan persamaan regresi $Y=20,705+$ $0,572 X_{1}$, nila koefisien korelasi sebesar 0,620 artinya kedua variabel memiliki tingkat hubungan yang kuat dengan koefisien determinasi sebesar 38,5\%. Uji hipotesis diperoleh $\mathrm{t}$ hitung $>\mathrm{t}$ tabel atau $(6,226>1,999)$. Dengan demikian $\mathrm{H}_{0}$ ditolak dan $\mathrm{H}_{1}$ diterima artinya terdapat pengaruh signifikan antara kepemimpinan terhadap kinerja karyawan di PT. Victory Chingluh Indonesia Divisi Quality.

2. Lingkungan kerja berpengaruh signifikan terhadap kinerja karyawan PT. Victory Chingluh Indonesia Divisi Quality dengan persamaan regresi $\mathrm{Y}=$ $11,637+0,761 X_{2}$ nilai koefisien korelasi sebesar 0,800 artinya kedua variabel memiliki tingkat hubungan yang sangat kuat dengan koefisien determinasi sebesar $64,1 \%$. Uji hipotesis diperoleh $\mathrm{t}$ hitung $>\mathrm{t}$ tabel atau $(10,513>1,999)$. Dengan demikian $\mathrm{H}_{0}$ ditolak dan $\mathrm{H}_{2}$ diterima artinya terdapat pengaruh signifikan antara lingkungan kerja terhadap kinerja karyawan (Y) di PT. 
Victory Chingluh Indonesia Divisi Quality.

3. Kepemimpinan dan lingkungan kerja berpengaruh signifikan terhadap kinerja karyawan PT. Victory Chingluh Indonesia Divisi Quality dengan persamaan regresi $\mathrm{Y}=7,374+0,230 \mathrm{X}_{1}+$ $0,628 X_{2}$. Nilai koefisien korelasi diperoleh sebesar 0,826 artinya variabel bebas dengan variabel terikat memiliki tingkat hubungan yang sangat kuat dengan koefisien determinasi atau pengaruh secara simultan sebesar $68,3 \%$ sedangkan sisanya sebesar 31,7\% dipengaruhi faktor lain. Uji hipotesis diperoleh nilai $F_{\text {hitung }}>F_{\text {tabel }}$ atau $(65,719$ $>2,760$ ). Dengan demikian $\mathrm{H}_{0}$ ditolak dan $\mathrm{H}_{3}$ diterima. Artinya terdapat pengaruh signifikan secara simultan antara kepemimpinan dan lingkungan kerja terhadap kinerja karyawan di PT. Victory Chingluh Indonesia Divisi Quality.

\section{Saran}

1. Kepemimpinan pernyataan yang paling lemah adalah nomor 1 yaitu perilaku pemimpin selama ini meberikan suri tauladan yang baik, dimana hanya mencapai rata-rata score sebesar 3,39. Untuk lebih baik lagi maka pimpinan hendaknya mampu berperilaku yang baik sehingga dapat dijadikan contoh oleh karyawan.

2. Lingkungan kerja pernyataan yang paling lemah adalah nomor 1 yaitu penerangan ditempat kerja cukup baik dan tidak menyilaukan sehingga mendukung aktivitas kerja, dimana hanya mencapai rata-rata score sebesar 3,38 . Untuk lebih baik lagi perusahaan harus memperbaiki fasilitas penerangan sesuai kebutuhan agar mampu melancarkan aktifitas pekerjaan karyawan.

3. Kinerja karyawan pernyataan yang paling lemah adalah nomor 1 yaitu kualitas pekerjaan yang dihasilkan akan mempengaruhi promosi jabatan, dimana hanya mencapai rata-rata score sebesar 3,39. Untuk lebih baik lagi perusahaan hendaknya memberikan reward kepada karyawan yang memiliki kemampuan menciptakan produk yang berkualitas.

\section{DAFTAR PUSTAKA}

Abdullah, M. Ma'ruf, "Manajemen dan Evaluasi Kinerja Karyawan", Aswara Pressindo, Jakarta 2014.

Algifari, (2015), Analisis Regresi untuk Bisnis dan Ekonomi, Yogyakarta: BPFE.

Amelinda Putri, Nurlaely dan Heri Subagy, 2018, Pengaruh Gaya Kepemimpinan dan Lingkungan Kerja terhadap Kinerja Karyawan pada PT BPR Argo Cipta Adiguna Pare. Jurnal Penelitian Ekonomi - Universitas Kadiri, Kediri. Volume 1 No 1, ISSN 2621-2374.

Amirullah, 2015, Pengantar Manajemen, Jakarta: Mitra Wacana Media.

Anwar Prabu Mangkunegara, (2016) Sumber Kerangka Berfikir Kinerja, Jakarta: PT. Gramedia.

Danang Sunyoto, (2015) Analisis Data Ekonomi Dengan Menggunakan SPSS, Cetakan I, Jakarta: Penerbit PT. Indeks.

Edy Sutrisno, (2016) Sumber Daya Manusia, Surabaya: PT. Gramedia.

Eko Widodo, Suparno, "Manajemen Pengembangan Sumber Daya Manusia", Cetakan I dan II. Yogyakarta, 2015.

Fahmi, Irham, "Manajemen Sumber Daya Manusia Teori dan Aplikasih", Alfabeta, Bandung, 2016.

Gandung, M., \& Suwanto, S. (2020). Analisis Pengaruh Kompensasi Dan Gaya Kepemimpinan Terhadap Kinerja Karyawan Pada PT. Surya Rasa Loka Jaya Di Jakarta Barat. JENIUS (Jurnal Ilmiah Manajemen Sumber Daya Manusia), 3(3), 236-245.

Gerry Dessler, (2016) Human Resources Management, Prenticehall, London: International Inc..

Ghozali, Imam, (2011), "Aplikasi Analisis Multivariate Dengan Program SPSS".

Hasibuan, S.P, Malayu, Organisasi dan Motivasi, Cetakan kedelapan, PT Bumi Aksara: Jakarta, 2015. 
Hermawati, R., et al. (2020). The Effect of Trilogy Leadership Style and Organization Culture on School Performance: Evidence form Indonesian Senior High School. PalArch's Journal of Archaeology of Egypt/Egyptology, 17(6), 8512-8537.

Imam Ghozali, (2017), Aplikasi Analisis Multivariate Dengan Program SPSS, Edisi Kelima, Semarang: Badan Penerbit Undip.

Istijanto, (2014), Riset Sumber Daya Manusia, Jakarta: PT. Gramedia Pustaka.

Malhotra, Naresh, K., and David F. Birks, 2012, Marketing Research: An Applied Approach $3^{\text {rd }}$ European Edition, Harlow, England: Prentice-Hall.

Mangkunegara, Prabu Anwar, (2015), Evaluasi Kinerja SDM, Cetakan ke tujuh, PT Refika Aditama: Bandung.

Meilawati, D., Rawi, R. D. P., Lewenussa, R., \& Bintari, W. C. (2019). Pengaruh Pemberian Insentif Terhadap Kinerja Karyawan Pada Pt Telesindoshop Kota Sorong. Manajemen Dewantara, 3(1), 128-137.

Melayu S.P, Hasibuan, "Manajemen Sumber Daya Manusia", Edisi Revisi Cetakan ke Sebelas, PT Bumi Aksara, Jakarta 2015.

Nitisemito, A. 2014, Pengelolaan Lingkungan Kerja Edisi Revisi, Bandung: PT. Aditama.

Nuraida, Ida, 2014, Manajemen Administrasi Perkantoran, Yogyakarta : Kanisisus.

Nurjaya, N., et al. (2021). Pengaruh Kompetensi Sumber Daya Manusia Dan Kemampuan Pemanfaatan Teknologi Terhadap Kinerja Aparatur Desa Pada Kantor Kepala Desa Di Kabupaten Gunungkidul, Yogyakarta. JENIUS (Jurnal Ilmiah Manajemen Sumber Daya Manusia), 4(3), 332-346.

Pawar, A., et al. (2020). Organizational Servant Leadership. International
Journal of Educational Administration, Management, and Leadership, 63-76.

Prawirosentono, Suryadi, (2015), Kinerja, Bandung: Alfabeta.

Rawi, R. D. P. (2017). Analisis Hubungan Motivasi Terhadap Kinerja Pegawai (Studi Kasus Pada Kantor Kecamatan Ruing Kabupaten Ngada Ntt). Jurnal Noken: Ilmu-Ilmu Sosial, 2(2), 15-28.

Sinambela, Lijan Poltak, (2016), Manajemen Sumber Daya Manusia, Jakarta: PT Bumi Aksara.

Singgih Santoso, (2015), Menguasai Statistik Multivariat, Jakarta: PT Elex Media Komputindo.

Sondang P. Siagian, (2016), Manajemen Sumber Daya Manusia, Bumi Aksara, Jakarta.

Sri Widodo, 2016, Manajemen Sumber Daya Manusia: Teori, Perencanaan Strategi, Isu-isu Utama dan Globalisai, Manggu Media, Bandung.

Sudjana, (2014) Metode Statistika, Bandung: Tarsido.

Sugiyono, (2015), Metode Penelitian Administrasi : dilengkapi dengan Metode $R \mathcal{E} D$, , Alfabeta, Bandung.

Suharsimi Arikunto, (2014), Prosedur Penelitian Suatu Pendekatan Praktek, Jakarta: Rineka Cipta.

Suhartanto, (2014), Metode Riset Pemasaran, Bandung: Alfabeta.

Sunarsi, D., et al. (2021, January). The Influence of Motivation and Work Discipline on Employee Performance at the Yogyakarta Tourism Service. In Proceeding The First International Conference on Government Education Management and Tourism (Vol. 1, No.1, pp. 1-7).

Sutikno, 2014, Pemimpin dan Kepemimpinan PT. Holistica, Lombok.

Suwanto, S., et al. (2021). Pengaruh Motivasi Dan Pengalaman Kerja Terhadap Produktivitas Karyawan Pada Happy Restaurant Di Bandung. Jurnal Ekonomi Efektif, 3(4), 546-554. 